\title{
Het functioneren van de Accountant- Administratieconsulent nu en in de toekomst
}

J. Los

\section{Inleiding}

Met het in werking treden van de Wet op de Accountants-Administratieconsulenten (Wet AA) in 1974 is aan het accountantsberoep in Nederland een nieuwe dimensie toegevoegd: die van de specifiek op de kleine en middelgrote ondernemingen, agrarische sector, verenigingen, stichtingen en vrije beroepen gerichte Accountant-Administratieconsulent (AA). In de afgelopen 15 jaren heeft het AA-beroep zich stormachtig ontwikkeld. Zo staan inmiddels circa 3.300 AA's ingeschreven, zijn ruim 2.500 van hen in de openbare accountantspraktijk werkzaam, biedt de branche in totaliteit aan ruim 22.000 mensen werk en wordt de totale omzet van de AA-kantoren geschat op circa $f 2$ miljard. ${ }^{1}$ Uit deze cijfers kan worden afgeleid dat deze groep van accountants in een maatschappelijke behoefte voorziet. (Ter vergelijking: er zijn circa 2.600 registeraccountants in het openbaar accountantsberoep werkzaam met een geschatte gezamenlijke omzet van eveneens $f 2$ miljard).

In dit artikel zal worden ingegaan op de vraag welke de kenmerkende elementen in de accountantsfunctie van de Accountant-Administratieconsulent zijn die aan de groeiende vraag naar het beroep hebben bijgedragen. Daartoe zal allereerst kort worden ingegaan op de ontstaansgeschiedenis van het beroep Accountant-Administratieconsulent. Vervolgens zal in grote lijnen aandacht worden besteed aan de wijze waarop de Accountant-Administratieconsulent invulling geeft aan de uit zijn accountantsfunctie voortvloeiende controlerende en adviserende functie. Dat hierbij een parallel wordt getrokken met de collega's-registeraccountants is welhaast onvermijdelijk.

Ten slotte zal worden ingegaan op de toekomstige regelgeving ten aanzien van het accountantsberoep en de vraag op welke wijze hierin met de belangen van de Accountant-Administratieconsulent rekening zou moeten worden gehouden.

\section{Ontstaansgeschiedenis}

Aan het eind van de jaren zestig bestond er bij een groot aantal kleine en middelgrote ondernemingen en instellingen niet alleen grote behoefte aan administratieve dienstverlening, maar ook aan een meer continue begeleiding. Door vrije beroepsbeoefenaren werd weliswaar ingespeeld op deze behoefte, maar enige indicatie omtrent de vakbekwaamheid ontbrak. Bovendien bleek het merendeel van hen in het geheel niet georganiseerd. De wetgever huldigde het standpunt dat 'het zowel in het belang van de ondernemingen in het midden- en kleinbedrijf, maar eveneens voor de bonafide en deskundige beroepsbeoefenaren wenselijk is, dat formele waarborgen worden geschapen ter verzekering van de deskundigheid van deze personen en dat de voldoende gekwalificeerden zich door hun beroepsaanduiding onderscheiden'. ${ }^{2}$ Bovendien wees de wetgever

J. Los, accountant-administratieconsulent, is lid van de maatschap LVE Accountants en belastingconsulenten, verbonden aan Deloitte Dijker Van Dien. 


\section{MAB}

op het feit 'dat een wettelijke regeling van belang zal kunnen zijn met het oog op de liberalisatie in het gebied van de EEG van werkzaamheden op financieel, economisch en boekhoudkundig gebied, aangezien er een neiging bestaat om deze liberalisatie te koppelen aan een wettelijke status van de betrokkken dienstverleners. ${ }^{3}$

In de wettelijke regeling die toen tot stand kwam via de Wet op de Accountants-Administratieconsulenten werd een beschrijving opgenomen van de voor het beroep van Accountant-Administratieconsulent karakteristieke handelingen:

a het inrichten van doelmatige administraties, het beoordelen van de wijze waarop een administratie wordt gevoerd, het opstellen van jaarstukken, dan wel het voeren van een administratie;

b het in een toelichtend rapport analyseren of interpreteren van aan een administratie ontleende gegevens, dan wel het, mondeling of schriftelijk, doen van mededelingen omtrent, of geven van een advies op grondslag van die gegevens'. ${ }^{4}$

Het beroep van Accountant-Administratieconsulent heeft zich, zoals in de inleiding van dit artikel reeds is aangegeven, in de afgelopen 15 jaar sterk ontwikkeld. Niet alleen is de omvang van de werkzaamheden in deze periode sterk toegenomen, ook de aard van de verrichte werkzaamheden verschoof en breidde zich uit. Deze uitbreiding, respectievelijk verschuiving, was zelfs zodanig dat de wetgever besloot de opsomming van de tot het beroep behorende karakteristieke werkzaamheden aan te passen aan de gewijzigde situatie. $\mathrm{Na}$ de wetswijziging van 11 december 1986 worden de volgende werkzaamheden tot het beroep van Accountant-Administratieconsulent gerekend: ${ }^{5}$

a het inrichten van een doelmatige administratie;

$b$ het voeren van een administratie, dan wel het verlenen van bijstand daarbij;

$c$ het beoordelen van een administratie op haar doelmatigheid en functioneren;

d het ontwerpen van jaarstukken en andere verantwoordingen;

e het onderzoeken van administraties, jaarstukken en andere verantwoordingen en het schrif- telijk vastleggen van de bevindingen omtrent dit onderzoek, dan wel het afgeven van schriftelijke verklaringen op basis van dit onderzoek; $f$ het analyseren en interpreteren van aan een administratie, aan jaarstukken of andere verantwoordingen ontleende gegevens of het geven van advies op grondslag van die gegevens;

$\mathrm{g}$ het verrichten van werkzaamheden van fiscale aard, voor zover deze voortvloeien uit of samenhangen met de hierboven genoemde handelingen.

Gaan wij de oorzaken na die leidden tot de uitbreiding respectievelijk verschuiving in de werkzaamheden dan constateren wij het volgende:

- een stijgend opleidingsniveau van de ondernemer, waardoor hij ook zelf zijn administratie gaat voeren, resulteert in het algemeen in een grotere cijfermatige interesse voor het bedrijfsgebeuren. De ondernemer gaat in dergelijke situaties hogere eisen stellen aan de adviesdiensten van de Accountant-Administratieconsulent;

- een steeds ingewikkelder wordende wetgeving op financieel-economisch en fiscaal terrein, en een daardoor toenemende vraag naar controle en advisering op een breed terrein;

- een toenemende mate waarin de overheid deelverklaringen bij financiële bescheiden aan Accountants-Administratieconsulenten toewijst.

\section{Accountantsfunctie}

$\mathrm{Na}$ deze uiteenzetting over de ontwikkeling van het beroep van Accountant-Administratieconsulent en de tot dit beroep behorende specifieke werkzaamheden willen wij thans nader ingaan op de wijze waarop de Accountant-Administratieconsulent zijn accountantsfunctie vervult.

Ten aanzien van die accountantsfunctie wordt in de literatuur ${ }^{6}$ wel het onderscheid gemaakt tussen de algemene en de specifieke accountantsfuncties. De algemene accountantsfunctie richt zich met name op het controleren ten behoeve van het maatschappelijk verkeer en het controleren en adviseren ten behoeve van de bedrijfslei- 


\section{MAB}

ding. Het vertrouwen dat alle bij de desbetreffende huishouding betrokkenen ('het maatschappelijk verkeer') hebben in de deskundigheid, onafhankelijkheid en integriteit van de accountant is van wezenlijke betekenis voor deze functie. Wat deze laatste eigenschappen betreft kan worden geconstateerd dat, gelet op de groeiende vraag naar diensten van de Accountant-Administratieconsulent, het maatschappelijk verkeer een groot vertrouwen heeft in diens vakbekwaamheid en onpartijdigheid. De beschermende (preventieve) werking van de beroepsregels en het feit dat het aantal tuchtrechtelijke procedures omtrent misslagen in de uitoefening van het AA-beroep tot op heden zeer gering genoemd mag worden, ${ }^{7}$ hebben hiertoe zeker een positieve bijdrage geleverd.

Beperken wij ons ten aanzien van de accountantsfunctie tot de controlegerichte werkzaamheden, dan kan worden geconcludeerd dat de Accountant-Administratieconsulent met name bij het verrichten van de in artikel 31 lid 2 sub e genoemde werkzaamheden zal optreden in zijn algemene accountantsfunctie. De verantwoordingen worden door hem gecontroleerd ('onderzocht') en op basis van dit onderzoek geeft hij zijn bevindingen dan wel zijn verklaring ${ }^{8}$ af ten behoeve van de ondernemingsleiding en/of het maatschappelijk verkeer. Om een goed inzicht te krijgen in de betekenis van deze accountantsuitingen zal nader worden ingegaan op de door de AA te verrichten controlewerkzaamheden.

\section{Controleverrichtingen}

De Accountant-Administratieconsulent dient op grond van zijn beroepsregelen zijn werkzaamheden eerlijk, nauwgezet en naar beste vermogen te verrichten. ${ }^{9}$ In geval van een jaarrekening beoordeelt de Accountant-Administratieconsulent op zijn minst de deugdelijkheid van de aangeleverde cijfers. De omvang en diepgang van een dergelijk onderzoek kan verschillen naar gelang van bijvoorbeeld de aard van de betrokken onderneming en de kwaliteit van de administratieve organisatie. Daarnaast beoordeelt hij de gegevens op kwantitatieve en rubriceringsaspecten, toetst hij de essentiële posten uit die jaarrekening op aan- nemelijkheid en staat hij, als vakman, borg voor een verantwoorde toepassing van de vigerende waarderings- en presentatievoorschriften. Deze werkzaamheden worden wel aangemerkt als de 'natuurlijke controlefunctie' van de AA. Dit betekent dat zij niet alleen bij controle-opdrachten, maar ook bij opdrachten tot administratieve dienstverlening worden toegepast.

Naast de natuurlijke controlefunctie kent de Accountant-Administratieconsulent ook een specifieke controlefunctie. Deze specifieke controlefunctie vloeit rechtstreeks voort uit de opdracht om de mate van betrouwbaarheid van financiële stukken te onderzoeken.

Het onderzoek door de AA kent een aantal gradaties: zij kan lopen van een onderzoek naar de aannemelijkheid (het minimum ingevolge de natuurlijke controlefunctie van de $A$ A) tot een onderzoek naar de getrouwheid (juistheid, tijdigheid, volledigheid). Bedoelde gradaties vinden voornamelijk hun uitwerking in de materiële controle. Aan de formele controle (naleving van voorschriften en dergelijke) worden geen concessies gedaan.

Zie hier het verschil met de door de registeraccountant in zijn accountantsfunctie verrichte controlewerkzaamheden: deze kan zich slechts richten op het onderzoeken van de getrouwheid van de verantwoording. Voldoet het onderzoek niet aan dit vereiste, dan vervalt de registeraccountant automatisch in het gebruik van de verplicht voorgeschreven bewoordingen 'geen accountantscontrole toegepast' dan wel 'niet gecontroleerd'. ${ }^{10}$ Dat er ondanks deze vermelding wel degelijk enige toetsende werkzaamheden hebben plaatsgevonden, maar dat die geen onderdeel uitmaken van een alles omspannende volkomen controle en daarom niet als 'accountantscontrole' mogen worden aangeduid, is voor zeer veel ondernemers uit het midden- en kleinbedrijf volkomen onbegrijpelijk. En het zijn met name deze kleine ondernemingen waar de registeraccountant, vanwege een ontbreken van een afdoende controletechnische functiescheiding, niet tot een goedkeurend of afkeurend oordeel kan komen. De Accountant-Administratieconsulent zal in deze situaties zijn onderzoek kunnen richten op de aannemelijkheid van de financiële 


\section{MAB}

verantwoording en daarop zijn controlemix afstemmen.

In de wijze waarop de Accountant-Administratieconsulent zijn controlemix samenstelt manifesteert zich een tweede belangrijk verschil met de controlewerkzaamheden der registeraccountants.

Gegeven het feit dat het met name om kleine organisaties gaat waarbinnen interne controle om bedrijfseconomische redenen veelal niet optimaal kan worden doorgevoerd, zal de Accountant-Administratieconsulent trachten met een andere dosering van zijn controlemiddelen zoveel mogelijk inzicht te krijgen in de aannemelijkheid van de verantwoording.

Het zijn daarbij, uiteraard afhankelijk van de omvang van de organisatie en de mate van controletechnische functiescheiding, naast de beoordeling van de administratieve organisatie, bij kleine organisaties met name de cijferbeoordeling, de waarnemingen ter plaatse en de inlichtingen van gecontroleerde die aan importantie winnen. Zo zal de Accountant-Administratieconsulent bij zijn cijferbeoordeling de samenhang tussen de verschillende onderdelen van het bedrijfsgebeuren nagaan. Daarnaast valt onder de cijferbeoordeling ook de vergelijking met voorgaande jaren en/of begroting, de toetsing van de brutowinst (eventueel aan branche-georiënteerde kengetallen).

De kleinschaligheid van het midden- en kleinbedrijf brengt met zich mee dat de AccountantAdministratieconsulent, als financieel deskundige die met regelmaat zijn cliënt bezoekt, veelvuldig wordt geraadpleegd bij problemen waarmee de ondernemer zich geconfronteerd ziet. De vertrouwensrelatie, die aldus in de loop der jaren wordt opgebouwd maakt, dat er een open communicatie ontstaat tussen ondernemer en accountant. Als gevolg hiervan, en door de beperkte inzetbaarheid van andere controlemiddelen, nemen de betekenis van 'inlichtingen van gecontroleerde' en 'waarnemingen ter plaatse' als controlemiddelen toe.

Voor menig ondernemer in het midden- en kleinbedrijf verzorgt de Accountant-Administratieconsulent bovendien de aangifte inkomstenbelasting en vermogensbelasting. Gelet op het feit dat het in deze situaties in het algemeen gaat om directeur/eigenaren geeft dit de Accountant-Administratieconsulent een extra middel in handen om de inkomstenverantwoording van de onderneming te toetsen.

\section{Accountantsuitingen}

$\mathrm{Na}$ afronding van zijn werkzaamheden zal de Accountant-Administratieconsulent zijn bevindingen rapporteren aan zijn opdrachtgever. Dit doet hij door middel van het rapport van accountantsbevindingen, waarbij uiteraard bij de keuze van de bewoordingen rekening wordt gehouden met de aard van de opdracht en de uitkomsten van het onderzoek.

Met dit rapport wordt inzicht verschaft in de mate van betrouwbaarheid van de onderzochte financiële rekening en verantwoording zonder dat een oordeel over die verantwoording wordt uitgesproken. Er worden namelijk uitsluitend door de accountant gedane (relevante) waarnemingen vermeld welke voor het beoordelen van de jaarrekening van belang kunnen zijn.

En daarmee zijn wij aangeland bij het derde belangrijke verschilpunt tussen de accountantsfunctie van de Accountant-Administratieconsulent en die van de registeraccountant. De Accountant-Administratieconsulent vervult met zijn rapport van accountantsbevindingen een attesterende functie: de door hem afgegeven bevindingen hebben een evaluerend/informerend karakter. ${ }^{11}$ Het is aan de gebruiker van de bevindingen om zich een oordeel te vormen. Dit oordeel hoeft evenwel niet uitsluitend gebaseerd te zijn op algemene eisen, zoals die van getrouwheid, maar kan mede beïnvloed worden door specifieke, van gebruiker tot gebruiker verschillende eisen. De registeraccountant zal er naar streven in deze situatie op te treden in zijn certificerende functie, hetgeen inhoudt dat aan de gebruiker van het oordeel (in casu de verklaring) bevestigd wordt dat aan bekende vereisten is voldaan. Veelal zal de registeraccountant, vanwege de beperkte omvang van de ondernemingen in het midden- en kleinbedrijf en de daaruit voortvloeiende onzekerheden in de controle, niet tot een stellig oordeel omtrent de verantwoording kun- 


\section{MAB}

nen komen, hetgeen impliceert dat een zogenaamde 'oordeelonthouding' moet worden afgegeven. Een dergelijk oordeel blijkt in de praktijk op bijna evenveel onbegrip te stuiten als de vermelding 'geen accountantscontrole toegepast' in situaties waarin geen onderzoek naar de getrouwheid is (of kon worden) ingesteld. ${ }^{12}$

\section{Adviesfunctie}

Tijdens zijn werkzaamheden bij de onderneming wordt de accountant regelmatig geconfronteerd met onvolkomenheden en/of tekortkomingen in bestaande procedures of in de wijze van administreren. Het wordt als een vanzelfsprekendheid beschouwd dat de accountant de ondernemingsleiding van deze constatering op de hoogte stelt en haar daarbij tevens adviseert omtrent de wijze waarop deze onvolkomenheden c.q. tekortkomingen kunnen worden opgeheven (de zogenaamde natuurlijke adviesfunctie). Naast deze rechtstreeks uit de algemene accountantsfunctie voortvloeiende natuurlijke adviesfunctie kent de accountant ook nog een specifieke adviesfunctie: deze wordt ingesteld door aanvaarding van een expliciete opdracht tot het verstrekken van advies. Een dergelijke opdracht kan door een cliënt worden gegeven op grond van door de accountant gesignaleerde problematiek; of op grond van een door de cliënt zelf gestelde vraag. Kenmerkend voor kleine en veel middelgrote ondernemingen, in vergelijking met grote(re) ondernemingen, is de geringere omvang en daaraan gekoppeld het ontbreken van (sommige) stafafdelingen waarin deskundigheden zijn ondergebracht die niet tot de kernactiviteit van de onderneming behoren. Door het ontbreken van deze verbijzonderde deskundigheid zal de leiding van veel van die ondernemingen, die zich met een probleem geconfronteerd zien, een beroep moeten doen op een extern adviseur. Het ligt daarbij voor de hand dat zij in eerste instantie een beroep doet op de adviseur die reeds regelmatig bij haar op bezoek komt, die haar bedrijf reeds door en door kent en met wie zij een vertrouwensrelatie heeft opgebouwd: de Accountant-Administratieconsulent. Door zijn brede opleiding en ervaring zal de Accountant-Administratieconsulent een groot aantal vragen direct kunnen beantwoorden. In die situaties waarin zijn kennis tekort schiet zal de Accountant-Administratieconsulent de leiding doorverwijzen naar ter zake meer deskundigen of in samenwerking met die deskundigen aan een oplossing werken.

Voor een aantal AA-kantoren betekent dit doorverwijzing naar andere zelfstandig gevestigde vrije beroepsbeoefenaren. Andere AA-kantoren daarentegen hebben veelgevraagde specialismen binnen de eigen organisatie beschikbaar en kunnen hun cliënten daardoor een multidisciplinair dienstenpakket aanbieden. Veel advieswerk dat door de Accountant-Administratieconsulent, soms samen met andere deskundigen, wordt verzorgd ligt op het gebied van:

- administratieve organisatie;

- beoordeling prognoses;

- keuze rechtsvorm;

- opvolgingsproblematiek;

- automatisering;

- subsidies;

- te kiezen verzekeringen;

- financieringsvormen/-structuur;

- waarderingsproblematieken.

Verwacht mag worden dat, als een gevolg van de steeds complexer wordende maatschappij en de toenemende snelheid waarmee zich daarbinnen veranderingen voltrekken, deze doorverwijsfunctie/samenwerking de komende jaren in belangrijkheid zal toenemen en dat AA-kantoren op deze tendens zullen inspelen door zich te ontwikkelen in de richting van meerdienstenorganisaties of door op andere wijze samenwerkingsverbanden te ontwikkelen. Uiteraard zal dit dienen te geschieden binnen het (ruime) kader van de voor de Accountant-Administratieconsulent geldende beroepsregelen. In concreto betekent dit dat geen samenwerking is toegestaan met beroepsgroepen die de onafhankelijkheid van de Accountant-Administratieconsulent in gevaar zouden kunnen brengen en dat de samenwerkingspartners onderworpen dienen te zijn aan beroepsregelen en tuchtrechtspraak vergelijkbaar met die van de Accountant-Administratieconsulent. ${ }^{13}$

Van enig preventief toezicht op de samenwer- 


\section{MAB}

king, bijvoorbeeld in de vorm van de noodzaak tot het verkrijgen van een mededeling van aanvaarding, ${ }^{14}$ is evenwel geen sprake. Het wordt aan het eigen inzicht van de Accountant-Administratieconsulent overgelaten of hij het noodzakelijk acht nadere voorwaarden te stellen aan de samenwerkingsvorm, opdat de medeverantwoordelijkheid kan worden gedragen. Deze handelwijze sluit nauw aan bij het door de regering gehuldigde standpunt ten aanzien van deregulering. Bovendien legt zij de verantwoordelijkheid daar waar zij naar huidige maatschappelijke opvatting behoort te liggen, namelijk bij de direct betrokkene(n).

\section{Toekomst}

Uit het vorenstaande kan worden geconcludeerd, dat het beroep van Accountant-Administratieconsulent zich in haar vijftienjarig bestaan een brede maatschappelijke erkenning heeft weten te verwerven. De door de Accountant-Administratieconsulent aangeboden diensten voorzien in een duidelijke behoefte. Niet alleen de kleine maar ook de middelgrote ondernemingen weten de Accountant-Administratieconsulent in zijn accountantsfunctie op waarde te schatten. Een accountantsfunctie waaraan de AccountantAdministratieconsulent op onderdelen een duidelijk van zijn collega de registeraccountant afwijkende invulling heeft gegeven. En het zijn met name deze afwijkingen (het onderzoeken van de betrouwbaarheid in gradaties, het gebruik van een specifiek op de kleine en middelgrote ondernemingen afgestemde controlemix, het in begrijpelijke bewoordingen rapporteren van bevindingen, het - gevraagd of ongevraagd - adviseren op een zeer breed terrein) waardoor de dienstverlening van de Accountant-Administratieconsulent werd afgestemd op de behoefte van de afnemers van zijn diensten.

Thans, augustus 1989, staat het accountantsberoep aan de vooravond van enkele ingrijpende wijzigingen in de Nederlandse accountantswetgeving.

Niet alleen dient de wet te worden aangepast aan de Achtste EG-Richtlijn (inzake de toelating van personen belast met de wettelijke controle van boekhoudbescheiden) maar bovendien heeft de Minister van Economische Zaken deze noodzakelijk geworden wetswijziging aangegrepen om, in het kader van het streven van de overheid naar deregulering, tot stroomlijning van de accountantswetgeving over te gaan.

Met betrekking tot dit laatste, de stroomlijning van de accountantswetgeving, ben ik van mening dat het uitgangspunt dient te zijn dat de Accountant-Administratieconsulent zich ook in de toekomst in voldoende mate moet kunnen blijven profileren naar zijn huidige werkterrein. De markt vraagt hierom en het deskundigheidsniveau is er. In afwachting van de definitieve stroomlijningswetgeving, waarin ook het wettelijk controleurschap zal worden geregeld, dienen aan de beroepsuitoefening door de Accountant-Administratieconsulent in ieder geval geen nieuwe beperkingen te worden opgelegd en zal gedwongen cliëntenverlies zo veel mogelijk dienen te worden voorkomen. In dit verband ben ik dan ook van mening dat er alsnog op korte termijn een overgangsregeling dient te worden getroffen voor die Accountants-Administratieconsulenten die, door de uitbreiding van de controleplicht tot middelgrote besloten vennootschappen, thans gedwongen worden de werkzaamheden voor deze cliënten te beëindigen en de jarenlang bestaande (vertrouwens)relatie te verbreken. De in de praktijk wel voorkomende situatie waarin een Accountant-Administratieconsulent voor het verkrijgen van een verklaring omtrent de getrouwheid tijdelijk een registeraccountant inschakelt, kan naar mijn mening geen structurele oplossing zijn en doet bovendien tekort aan de positie die de Accountant-Administratieconsulent zich inmiddels heeft verworven.

Er dient derhalve een overgangsregeling te komen die zou kunnen eindigen op het moment dat de Nederlandse wetgeving is aangepast aan de Achtste EG-Richtlijn. Op dat moment zal immers de definitieve regeling met betrekking tot het wettelijk controleurschap in werking treden. Een regeling waarbinnen naar mijn mening ook een plaats zal moeten worden ingeruimd voor de huidige Accountant-Administratieconsulent, en wel om de volgende redenen: 


\section{MAB}

- de wetgever heeft dit bij de totstandkoming van de wettelijke regeling van het beroep Accountant-Administratieconsulent in het vooruitzicht gesteld; ${ }^{15}$

- de Accountant-Administratieconsulent voldoet aan nagenoeg alle (minimum) vereisten die daartoe in de Achtste EG-Richtlijn zijn gesteld.

Slechts zijn opleiding op het vakgebied 'accountantsonderzoek' zou op onderdelen aanvulling behoeven:

- in Nederland is in toenemende mate een overlapping van werkterrein en functie ontstaan tussen Accountant-Administratieconsulent en registeraccountant, waardoor de reden voor de tweedeling van het accountantswezen in Nederland in afzonderlijke beroepsgroepen steeds meer wegvalt;

- het dereguleringsstreven van de Nederlandse overheid behoort in samenhang met de stroomlijningsoperatie tot één beperkt van opzet zijnde accountantswet te leiden, die slechts betrekking zal hebben op één groep beroepsbeoefenaren;

- de veranderende beroepsbeoefening van de Accountant-Administratieconsulent, waarbij het aandeel van de administratieve dienstverlening steeds meer verschuift naar controleopdrachten in combinatie met advisering en begeleiding vereist een verdergaande certificeringsbevoegdheid voor deze beroepsgroep;

- de Accountant-Administratieconsulent heeft, wil hij in het accountantsberoep een toekomst hebben, een status nodig, waarmee hij - als gevolg van het toenemende grensoverschrijdende verkeer van zijn cliënten - ook in het buitenland direct herkenbaar en plaatsbaar is.

Bij de implementatie van de Achtste EG-Richtlijn dient verder nog rekening te worden gehouden met de recent afgekomen 11e EG-Richtlijn betreffende het algemeen stelsel van erkenning van hoger onderwijsdiploma's. Hiermee is voor accountants de mogelijkheid geopend om zonder belemmerende additionele eisen het beroep ook in andere lidstaten te kunnen uitoefenen.

Dit is nu verder alleen mogelijk indien het kwali- teitsniveau van de wettelijk controleurs binnen de EG onderling niet te veel van elkaar afwijkt.

Ook de wijze waarop de invoering van de Achtste EG-Richtlijn in de ons direct omringende landen is geschied, dient daarbij als voorbeeld te worden genomen. Bestaande beroepsgroepen, die voorzagen in een dienst waaraan in de markt sterk behoefte was, zijn daar op een uiterst soepele wijze in een overgangsregeling tot het wettelijk controleurschap gerechtigd.

De Nederlandse accountantswetgeving zal aldus op hoofdlijnen langs de hierna aangegeven route dienen te verlopen:

- de in de nieuwe accountantswet te stellen vakbekwaamheidseisen mogen niet hoger zijn dan strikt noodzakelijk is. Zij mogen niet belemmerend werken op de toetreding tot het accountantsberoep;

- het deskundigheidsniveau van de nieuwe accountant wordt aangegeven in de 8 e EGRichtlijn. Dit niveau, wat het gemiddelde is van de in de verschillende lidstaten geldende niveaus, dient op Europese wijze te worden uitgelegd. Dit teneinde een discriminatoire werking, daarbij mede gelet op de te verwachten effecten van de recente richtlijn inzake de wederzijdse erkenning van hogere onderwijsdiploma's, te voorkomen. De opleiding dient voldoende ruimte voor specialisaties, waaronder die voor het $M K B$, te bieden;

- de nieuwe wet dient het beroep van wettelijk controleur te regelen: het verrichten van door de wet verplicht gestelde controles van jaarrekeningen van ondernemingen en van andere instellingen. In de wet dienen naast de hierboven genoemde voorbehouden handelingen nog ten minste regelingen te worden opgenomen met betrekking tot titulatuur, tuchtrecht, bestuursstructuur, opleidingsvereisten en overgangsbepalingen;

- de overgangsregeling dient in overeenstemming met de elders gevolgde weg maximaal faciliterend van aard te zijn.

Aldus zou aan de gerechtvaardigde verlangens van een niet alleen in het 'midden- en kleinbedrijf' uiterst gerespecteerde beroepsgroep van Accountants-Administratieconsulenten op goede 


\section{MAB}

gronden en op een aanvaardbare wijze zijn tegemoet gekomen. Niet alleen in het belang van de beroepsbeoefenaren zelf, maar meer nog in het belang van het werkveld: de bijna 500.000 ondernemers in het 'midden- en kleinbedrijf' en de circa 100.000 ondernemers in de land- en tuinbouw, de beoefenaren van het vrije beroep en de bestuurders van verenigingen en stichtingen.

\section{Noten}

1 Drs. F. A. van Schaik AA, AA heeft stevige maatschappelijke positie verworven, te verschijnen in Accountant-Adviseurvan december 1989.

2 Memorie van Toelichting bij het ontwerp van wet, behorend bij de Koninklijke boodschap, pp. 9 ren $10 \mathrm{I}$.

3 Memorie van Toelichting bij het ontwerp van wet, behorend bij de Koninklijke boodschap, pp. 9 r en 101.

4 Artikel 31 lid 2 van de Wet op de Accountants-

Administratieconsulenten (vóór de wijziging van 11 december 1986).

5 Artikel 31 lid 2 van de Wet op de Accountants-

Administratieconsulenten.

6 Prof. Dr. A. B. Frielink RA c.s., Leerboek accountantscontrole, deel 1 Algemene Grondslagen, p. 31 e.v.

7 Tot op heden is in de tuchtrechtspraak slechts in twee situaties een misslagen in de uitoefening van het beroep van Accountant-Administratieconsulent geconstateerd (zie de arresten 1985/02 en 1987/03).
8 Artikel 31 lid 3 Wet AA bepaalt: 'De schriftelijk vastgelegde bevindingen en de schriftelijke verklaring ... houden niet in een oordeel omtrent de getrouwheid van een financiële rekening en verantwoording als bedoeld in artikel 70a van de Wet op de Registeraccountants'.

9 Artikel 2 van de Regelen Beroepsuitoefening AccountantsAdministratieconsulenten (RBAA).

10 Artikel 6 van de Gedrags- en'beroepsregels

registeraccountants (GBR).

11 F. W. van der Reek AA, Een marsroute in federatief RA/AA verband?, Accountant-Adviseur, oktober 1988.

12 Zie voor de wijze waarop de verklaring omtrent de getrouwheid door het maatschappelijk verkeer wordt beoordeeld: F. Drieënhuizen R.A., Opvattingen over accountants; een feedback voor theorie en praktijk, De Accountant, maart 1987, p. 300 .

13 Artikel 10 lid 2 van de Regelen Beroepsuitoefening Accountants-Administratieconsulenten (RBAA).

14 Artikel 24 GBR.

15 In de paragraaf over de ontstaansgeschiedenis van het beroep werd reeds melding gemaakt van het volgende, aan de Memorie van Toelichting bij het ontwerp van wet ontleende citaat: 'dat een wettelijke regeling van belang zal kunnen zijn met het oog op de liberalisatie in het gebied van de EEG van werkzaamheden op financieel, economisch en boekhoudkundig gebied, aangezien er een neiging bestaat om deze liberalisatie te koppelen aan een wettelijke status van de betrokken dienstverleners' (pp. 9 ren 10 l).

16 Zie artikel 4 van de Achtste EG-Richtlijn.

17 Zie artikel 6 van de Achtste EG-Richtlijn. 